\title{
Avaliação dos processos de compras com dispensa de licitação: estudo em uma universidade federal
}

\author{
Carla Cristina da Silveira Trilha Mestranda em Administração Universitária. Universidade Federal de Santa Catarina (UFSC) Brasil. \\ carla.trilha@gmail..com \\ Guilherme Krause Alves Mestre em Administração Universitária. Universidade Federal de Santa Catarina (UFSC) Brasil. \\ guilhermealv@gmail.com \\ Rogério da Silva Nunes Doutor em Administração. Universidade Federal de Santa Catarina (UFSC) Brasil. \\ rognunes@msn.com
}

\section{RESUMO}

0 artigo analisa os processos de compra de materiais de consumo, em uma Instituição Federal de Educação Superior - IFES, por meio da dispensa de licitação, de acordo com o inciso II do artigo 24 da Lei n. ㅇ 8.666, de 21/06/1993. A base teórica do estudo foram as compras públicas, a gestão de processos e o mapeamento de processos. A pesquisa caracteriza-se como descritiva, documental e estudo de caso. Foram realizadas entrevistas com servidores no intuito de levantar o perfil e a descrição das atividades desempenhadas durante o processo de compra direta, empregando a planilha $5 \mathrm{~W} 2 \mathrm{H}$ para a análise qualitativa dos dados. Nos resultados foi apresentado como sugestão o mapeamento do processo, utilizando as metodologias BPMN e BPMS, que possibilitaram a visualização do processo como um todo, a identificação das inconsistências, o apontamento de melhorias na utilização dos recursos, bem como a identificação de todos os envolvidos e a interação entre eles.

Palavras chave: Gestão de processos. Mapeamento de processos. Dispensa de licitação.

\section{Evaluation of purchasing processes with waiver of bidding: a study at a federal university}

\begin{abstract}
The article analyzes the processes of purchase of consumer materials, in a Federal Institution of Higher Education - IFES, by means of waiver of bidding process, according to item II of article 24 of Law n. 8,666, dated 06/21/1993. The theoretical basis of the study was public procurement, process management and process mapping. The research is characterized as descriptive, documentary and case study. Interviews were conducted with servers in order to raise the profile and description of the activities performed during the direct purchase process, using the $5 \mathrm{~W} 2 \mathrm{H}$ worksheet for the qualitative analysis of the data. In the results, the mapping of the process was presented as a suggestion, using BPMN and BPMS methodologies, which allowed the visualization of the process as a whole, the identification of inconsistencies, the indication of improvement in the use of resources, as well as the identification of all those involved in the process and the interaction among them.
\end{abstract}

Keywords: Process management. Process mapping. Waiver of bidding. 


\title{
1 INTRODUÇÃO
}

0 desempenho do setor público é tema de grande interesse, pois afeta o bem-estar social e 0 desenvolvimento econômico do país. Uma das necessidades na gestão pública brasileira é o aumento da eficiência dos serviços prestad os para a população, respeitadas as necessidades de formalização burocrática, que proporcionam departamentalização e lentidão administrativa.

As fiscalizações dos órgãos de controle externo têm destacado a necessidade de uma ênfase na melhoria dos processos administrativos nas organizações públicas, de forma a atender os princípios constitucionais da eficiência e economicidade. Há, assim, a necessidade de utilização de técnicas que proporcionem tais melhorias. A gestão e o mapeamento dos processos estão entre as possibilidades que buscam otimizar a utilização de recursos financeiros, materiais e humanos. A gestão de processos permite analisar, planejar e executar melhor as atividades através da definição adequada de responsabilidades, uso dos recursos de modo mais eficiente, solução de problemas e a eliminação de atividades redundantes, aumentando a produtividade.

Partindo-se da premissa de que atos administrativos no setor público exigem embasamento legal, destaca-se a Constituição Federal de 1988 que diz, no seu art. 37, inciso XXI, que "a contratação de obras, serviços, compras e alienações, bem como a concessão e a permissão de serviços públicos pela Administração Pública seja feita mediante um procedimento prévio chamado de licitação" (BRASIL, 1988). Há exceções na legislação específica, entre as quais encontra-se a dispensa do procedimento licitatório, conhecida como compra direta, objeto do presente estudo.

\subsection{Objetivo geral}

Analisar o processo de compras de material de consumo em uma Instituição Federal de Educação Superior - IFES, por meio de dispensa de licitação, com base no inciso II do artigo 24 da Lei 8.666/1993.

\subsection{Objetivos específicos}

Para atingir o objetivo geral, este estudo tem como objetivos específicos:

a) Apontar as metodologias de mapeamento de processos mais citadas na bibliografia;

b) Levantar o número de compras por dispensa de licitação no Governo Federal e na IFES em estudo nos anos de 2012 a 2014;

c) Mapear o processo de compras de material de consumo por meio do dispositivo da Lei 8.666/1993, artigo 24, inciso II, da IFES em estudo;

\section{COMPRAS PÚBLICAS}

Em 21 de junho de 1993 foi sancionada a Lei n. ${ }^{\circ} 8.666$, que em seu art. $1^{\circ}$ "estabelece normas gerais sobre licitações e contratos administrativos pertinentes a obras, serviços, inclusive de publicidade, compras, alienações e locações no âmbito dos Poderes da União, dos Estados, do Distrito Federal e dos Municípios" (BRASIL, 1993).

Cabe destacar em especial 0 art. 3ำ que conceitua licitação:

\begin{abstract}
A licitação destina-se a garantir a observância do princípio constitucional da isonomia, a seleção da proposta mais vantajosa para a administração e a promoção do desenvolvimento nacional sustentável e será processada e julgada em estrita conformidade com os princípios básicos da legalidade, da impessoalidade, da moralidade, da igualdade, da publicidade, da probidade administrativa, da vinculação ao instrumento convocatório, do julgamento objetivo e dos que lhes são correlatos (BRASIL, 1993).
\end{abstract}

A Administração Pública deve valer-se, prioritariamente, de procedimento licitatório para suprir suas demandas de bens e serviços, selecionando a proposta mais vantajosa, visando à promoção do desenvolvimento nacional sustentável, com a observância do disposto nas normas do Direito Público, diferentemente do ente privado que realiza suas contratações de forma discricionária (GASPARINI, 2010). Porém, existem casos expressos na lei que viabilizam a dispensa de licitação, sua inexigibilidade ou, ainda, tornam-na dispensada. 
Como o interesse público é o fim a ser atingido pela Administração Pública, se a competição (licitação) se mostra contrária a este fim, ocorre a dispensa. As situações excepcionais aplicáveis à compra por dispensa estão explicitadas no artigo 24 da Lei 8.666/1993 (BRASIL, 1993). Para que a situação possa implicar dispensa de licitação, deve o fato concreto enquadrar-se no dispositivo legal, preenchendo todos os requisitos. No inciso II do artigo 24 da Lei 8.666/1993, a legislação prevê que é dispensável a licitação:

II: para outros serviços e compras de valor até $10 \%$ (dez por cento) do limite previsto na alínea "a", do inciso II do artigo anterior e para alienações, nos casos previstos nesta Lei, desde que não se refiram a parcelas de um mesmo serviço, compra ou alienação de maior vulto que possa ser realizada de uma só vez (BRASIL, 1993).

O limite citado acima, previsto na alínea "a" do inciso II do artigo 23 da Lei 8.666/1993 é de $R \$ 80.000,00$. Desta forma, o limite para aquisição por dispensa de licitação utilizando este dispositivo é de R\$ 8.000,00 (BRASIL, 1993).

\section{GESTÃO DE PROCESSOS}

Processo, segundo Hammer (1997, p. 05), "é um grupo de tarefas relacionadas que, juntas, geram um resultado que tem valor para o cliente". Já Davenport (1994, p. 07) argumenta que "um processo é [...] uma ordenação específica das atividades de trabalho no tempo e no espaço, com um começo, um fim, e inputs e outputs claramente identificados: uma estrutura para a ação". O mesmo autor complementa explicando que os processos têm elementos como custo, prazos, qualidade, produção e satisfação do cliente. Quando reduzimos os custos ou aumentamos a satisfação do cliente, melhoramos o processo em si.

Em uma definição semelhante, Oliveira (2007) explica que processo pode ser entendido como um conjunto estruturado de atividades sequenciais que apresentam relação lógica entre si, com a finalidade de atender e, preferencialmente, suplantar as necessidades e as expectativas dos clientes externos e internos da empresa. Harrington (1991) complementa dizendo que as atividades ou conjunto de atividades os quais chamamos de processo tomam um input e adicionam valor a ele utilizando os recursos disponibilizados pela organização, fornecendo um output ao cliente específico.

Existem cinco modelos básicos de processos, conforme o nível de materialidade. Do mais concreto para o mais abstrato, pode-se classificar como fluxo de material, fluxo de trabalho, série de etapas, atividades coordenadas e mudança de estados (GONÇALVES, 2000). 0 autor destaca que os processos são mais fáceis de observar dentro das fábricas. No entanto, nos escritórios, onde são realizadas as tarefas mais burocráticas, estes processos não são tão facilmente visíveis, sendo este fato intensificado pela utilização da informática. Os fluxos seguem pela rede, de forma virtual e não simplesmente observável.

Gonçalves (2000) também categoriza os processos, de forma geral, em processo de negócio ou de cliente, processos organizacionais ou de integração organizacional, e processos gerenciais, sendo que essa classificação leva em conta o objetivo finalístico do processo. Outra categorização, descrita por Martin (1996), leva em conta a capacidade de geração de valor para o cliente, podendo ser primários, quando geram este valor, ou de suporte, quando tem por objetivo proporcionar o apoio necessário para o correto funcionamento dos processos primários. Os processos também podem ser internos ou externos, dependendo se o local de execução de todas as etapas é dentro da mesma organização. $E$ também podem ser inter ou intraorganizacional, considerando se há ou não a participação de outras organizações no processo (GONÇALVES, 2000).

Quanto à definição de gestão de processos, Paim et al. (2009, p. 139) afirmam ser "um conjunto articulado de tarefas permanentes para projetar e promover o funcionamento e o aprendizado sobre os processos". Smith $e$ Fingar (2003) possuem a visão de que a gestão "está dentro de um processo evolutivo e passa por uma fase na qual não só os processos devem ser gerenciados e informatizados, mas deve haver uma integração e 'agilização' da lógica de melhorar e implementar processos, pois há uma necessidade permanente de mudança e de adaptação".

Melhorar processos é uma ação básica para as organizações responderem às mudanças que ocorrem constantemente em seu ambiente de atuação. [...] Qualquer organização produtiva, seja pública, privada ou do terceiro setor, tem, sem exceção, que coordenar o trabalho (PAIM et al., 2009, p. 25). 
Para Azevedo (2010), as vantagens da gestão de processos são:

a) Redução dos tempos de ciclo;

b) Diminuição de custos;

c) Melhoria da eficiência interna;

d) Melhoria da qualidade;

e) Aumentos da satisfação dos colaboradores e clientes.

Davenport (1994) entende que o problema não é o fato de as pessoas não compreenderem a tarefa à qual elas executam, mas de que forma esta tarefa se combina com as demais para gerar um determinado resultado. A perspectiva do processo é justamente a de ver todo o conjunto de tarefas realizadas para se obter este resultado. 0 autor explica que "de todos os processos de uma organização, os de gerenciamento são os mais mal definidos, e os que menos provavelmente serão vistos em termos de processos" (DAVENPORT, 1994, p. 321). Monteiro (1991) diz que, se os órgãos públicos puderem repassar aos usuários as melhorias provindas da revisão de seus processos, a sociedade ganhará com seus resultados. Passarão a ser vistos de mal necessário a bem desejado.

Existem diversas metodologias para a realização da gestão de processos, sendo que vários autores citam como principais as seguintes: Aperfeiçoamento de Processos Empresariais (APE), Metodologia IBM de Gerenciamento de Processos, Process Classification Framework (PCF), Business Process Management (BPM) e Business Process Management System (BPMS). (NUNES, 2014)

A Metodologia IBM de Gerenciamento de Processos foi a utilizada durante a pesquisa e análise dos dados realizadas para o presente trabalho. Ela possui três fases: definição do processo, análise do processo e melhoria do processo. Após o término da última fase, retorna à primeira para a realização da melhoria contínua. Cada uma dessas três fases possui etapas distintas para a sua consecução (IBM, 1990).

Entre outras definições, o Business Process Management (BPM) é descrito por DeBruin e Doebeli (2009, apud J uliatto et al., 2012, p. 4) "como solução para o negócio usando softwares ou tecnologias para automatizare gerenciar os processos". A Business Process Modeling Notation (BPMN) estabelece uma maneira didática para desenvolver processos que são muitas vezes complexos e de difícil visualização por todos os membros da organização (JULIATTO et al., 2012). A partir do BPM surgem o Business Process Management Systems (BPMS). Eles podem ser entendidos como um conjunto de instrumentos que buscam a melhoria do sistema de gestão (VERNER, 2004). São os recursos tecnológicos utilizados para, aplicando a BPMN, e, a partir da inserção dos dados relativos ao processo, gerar gráficos e fluxogramas utilizados para analisar e gerenciar os processos.

\section{MAPEAMENTO DE PROCESSOS}

Villela (2000, p. 50) explica que mapeamento de processos é "uma ferramenta gerencial analítica e de comunicação que têm a intenção de ajudar a melhorar os processos existentes ou de implantar uma nova estrutura voltada para processos". Segundo a autora, o mapeamento pode ser utilizado para analisar os processos, reduzir as falhas de integração dos sistemas, melhorar o entendimento dos processos e eliminar ou simplificar os que porventura necessitem de alterações.

Losekann et al. (2012) corroboram com a afirmação, dizendo que o objetivo da modelagem de processos é possibilitar a consolidação do conhecimento e a formulação de mudanças estruturais por meio de diagramas operacionais que permitem a visualização do comportamento dos processos.

Correia, Leal e Almeida (2002, p. 4) ressaltam que o mapeamento de processos "é extremamente reconhecido pelo importante papel que pode desempenhar", considerando que propicia o entendimento das estruturas do fluxo de trabalho e, desta forma, facilita as avaliações de eficiência e eficácia da organização, bem como direciona as ações para a correção das atividades.

Juliatto (2012) sugere algumas ferramentas para o mapeamento dos processos de uma organização, sendo uma delas a utilização de fluxogramas, valendo-se da notação BPMN e dos BPMS. No entanto, é necessária a coleta dos dados para que sejam posteriormente inseridos no BPMS e, desta forma, possibilitar uma melhor análise. Para a coleta dos dados, 0 autor indica a utilização da tabela 5W2H, sigla para What (o quê), Why (por que), When (quando), Where (onde), Who (quem), How (como) e How Much (quanto custa). A tabela 5W2H assegura a identificação das atividades da forma mais precisa possível, colhendo informações detalhadas e inclusive proposições a serem avaliadas para a melhoria do processo em questão. 
Desta forma, conforme as metodologias e ferramentas expostas, tem-se uma sequência de atividades a serem realizadas para o mapeamento e análise do processo em questão. Na primeira fase da Metodologia IBM de Gerenciamento de Processos, a definição dos processos, deverão ser obtidos os dados junto aos participantes do processo (IBM, 1990), por meio de questionário próprio e preenchimento da planilha 5W2H pelos mesmos. Esses dados devem ser consolidados de modo a convergir em uma única planilha $5 \mathrm{~W} 2 \mathrm{H}$, com a anuência de todos os participantes, de modo a se ter um retrato, o mais fiel possível, do processo. Em seguida, os dados são transpostos para um fluxograma, utilizando as metodologias e ferramentas do BPM, BPMN e BPMS (JULIATTO, 2012).

A partir da consolidação da planilha 5W2H, estabelece-se a análise inicial do processo, uma vez que é possível verificar algumas inconsistências no mesmo. No entanto, é a partir da construção do fluxograma, que deverá também ser consolidado junto aos participantes (JULIATTO, 2012), é que a segunda etapa da Metodologia IBM, a análise do processo, é de fato realizada. Por meio do fluxograma é possível verificar eventuais falhas no processo, tais como tarefas realizadas no momento incorreto, ou mesmo desnecessárias, gargalos, entre outros. Feita a análise, com base no estudo realizado, são propostas as possíveis alternativas de solução e a aprovação, ou não, destas propostas para implementação (IBM, 1990).

Segue-se então para a última etapa da Metodologia IBM, melhoria do processo, em que de fato são efetivadas e testadas as propostas de solução realizadas, bem como o controle. Finalizada esta última etapa, de modo a proporcionar a melhoria contínua do processo, retorna-se à primeira, recomeçando os passos da Metodologia IBM de Gerenciamento de Processos (IBM, 1990).

\section{PROCEDIMENTOS METODOLÓGICOS}

Com relação à metodologia, tomou-se como base Vergara (2009), que classifica a pesquisa em relação a do is aspectos: quanto aos fins e quanto aos meios. Quanto aos fins, a pesquisa caracteriza-se como descritiva e aplicada, pois tratou de fatos e fenômenos de determinada realidade, motivada pela necessidade de resolver um problema na prática. Quanto aos meios, a pesquisa é bibliográfica, documental e estudo de caso. Bibliográfica tendo em vista que, para a fundamentação teórica, foi realizada investigação de vários autores na área de gestão de processos e de mapeamento de processos, afim de se verificar a metodologia mais adequada para a IFES em estudo. Documental porque o levantamento das informações aconteceu por meio da análise dos documentos internos da IFES e dos relatórios gerados pelo sistema DW-SIASG - Sistema Integrado de Administração de Serviços Gerais do Governo Federal. Estudo de caso, pois abordou-se a situação específica de uma IFES, no qual foi possível conhecer minuciosamente os elementos referente a gestão de processos e mapeamento do Departamento de Compras, no que diz respeito aos processos de aquisição por meio de dispensa de licitação pelo previsto no inciso II do artigo 24 da Lei 8.666/1993.

Cabe esclarecer que o SIASG é o Sistema Integrado de Administração de Serviços Gerais do Governo Federal. Ele "é o sistema onde são realizadas as operações das compras governamentais dos órgãos integrantes do SISG (Administração Pública Federal direta, autárquica e fundacional)" (BRASIL, 2015b). O "DW" da sigla DWSIASG vem de Data Warehouse, sistema que integra "dados corporativos espalhados em diferentes sistemas de informação, para torná-los acessíveis a todos os usuários que precisam desses dados para tomar algum tipo de decisão" (PUCMG, 2015). Desta forma, o DW-SIASG é um sistema que cruza informações de diversos outros sistemas que fazem parte da estrutura do SIASG.

As técnicas de levantamento e coleta de dados utilizadas foram a observação direta, consultas ao sistema DW-SIASG e entrevistas realizadas com servidores para o levantamento do perfil e o preenchimento da planilha $5 \mathrm{~W} 2 \mathrm{H}$ com as etapas do processo. Os entrevistados foram definidos levando-se em consideração os seguintes critérios: (i) servidor estável da IFES, (ii) mínimo de 3 anos de experiência no Departamento de Compras e (iii) participação no processo estudado.

Os instrumentos de pesquisa foram um questionário e uma planilha $5 \mathrm{~W} 2 \mathrm{H}$, que foram enviados para cinco servidores que se encaixaram no perfil acima definido, dos quais retornaram quatro instrumentos respondidos. As perguntas do questionário foram as seguintes:
a) Quanto tempo atuam na IFES?
b) Quanto tempo atua no Setor de Compras da IFES?
c) Entre suas atribuições, já realizou o processo de compra direta (dispensa de licitação)?
d) A compra direta (dispensa de licitação) está entre suas atribuições atuais? 
e) Conhece os requisitos previstos na legislação específica?

f) Possui experiência com compras antes de ingressar na IFES?

g) Descreva o processo de aprendizagem dos procedimentos de compra direta.

h) Utiliza alguma ferramenta ou técnica de gestão nos procedimentos de compra direta? Qual(is)?

Obtidos os dados, a etapa seguinte foi a análise e a interpretação dos mesmos. Segundo Lakatos (1990), as análises podem ser quantitativas ou qualitativas. A análise realizada nesse artigo foi qualitativa, com a aquisição de dados sobre a realidade, buscando referencial bibliográfico da literatura para, a partir da fundamentação teórica, confrontar com a realidade. A pesquisa qualitativa pode ser caracterizada como sendo uma tentativa de explicar em profundidade o significado e as características do resultado das informações obtidas e com isso ser capaz de oferecer contribuições para o processo de mudanças.

\section{DESCRIÇÃO DO PROCESSO DE COMPRAS DIRETAS}

O processo de compra por meio de dispensa de licitação, utilizando o disposto no inciso II do artigo 24 da Lei 8666/1993, também conhecida como compra direta, foi escolhido por ser uma das modalidades mais utilizadas, em número de processos, na instituição pesquisada e também no âmbito da Administração Pública Federal. Além disso, muitas aquisições de emergência, para atender a demandas imprevistas, são realizadas desta forma, o que ressalta ainda mais a importância do gerenciamento adequado deste tipo de processo.

A Tabela 1, a seguir, apresenta as compras por modalidade nos órgãos do Governo Federal, nos anos de 2012 a 2014, cujos dados foram obtidos no sistema DW-SIASG.

Tabela 1 - Compras por modalidade nos órgãos do Governo Federal

\begin{tabular}{|c|c|c|c|}
\hline Ano & Modalidade de compra & Quantidade compras & Percentual no Ano \\
\hline \multirow{8}{*}{2012} & Convite & 1.019 & $0,37 \%$ \\
\hline & Tomada de Preços & 2.185 & $0,79 \%$ \\
\hline & Concorrência & 1.961 & $0,71 \%$ \\
\hline & Concorrência Internacional & 58 & $0,02 \%$ \\
\hline & Pregão & 65.156 & $23,57 \%$ \\
\hline & Dispensa de Licitação & 180.994 & $65,47 \%$ \\
\hline & Inexigibilidade de Licitação & 25.058 & $9,06 \%$ \\
\hline & Concurso & 16 & $0,01 \%$ \\
\hline \multirow{8}{*}{2013} & Convite & 791 & $0,29 \%$ \\
\hline & Tomada de Preços & 1.935 & $0,72 \%$ \\
\hline & Concorrência & 1.814 & $0,67 \%$ \\
\hline & Concorrência Internacional & 52 & $0,02 \%$ \\
\hline & Pregão & 71.229 & $26,35 \%$ \\
\hline & Dispensa de Licitação & 168.152 & $62,21 \%$ \\
\hline & Inexigibilidade de Licitação & 26.313 & $9,73 \%$ \\
\hline & Concurso & 24 & $0,01 \%$ \\
\hline \multirow{8}{*}{2014} & Convite & 596 & $0,24 \%$ \\
\hline & Tomada de Preços & 1.785 & $0,72 \%$ \\
\hline & Concorrência & 1.341 & $0,54 \%$ \\
\hline & Concorrência Internacional & 61 & $0,02 \%$ \\
\hline & Pregão & 69.237 & $28,03 \%$ \\
\hline & Dispensa de Licitação & 145.447 & $58,89 \%$ \\
\hline & Inexigibilidade de Licitação & 28.474 & $11,53 \%$ \\
\hline & Concurso & 45 & $0,02 \%$ \\
\hline
\end{tabular}

Fonte: Elaborado pelos autores a partir de Brasil (2015a)

Observa-se na tabela 1 que as dispensas de licitação representaram um grande percentual das aquisições realizadas pelo Governo Federal, superando os $50 \%$ em número de compras.

Na IFES em estudo, a questão não é diferente, pois a porcentagem de dispensas também é significativa, conforme Tabela 2. 
Tabela 2 - Compras por modalidade na IFES

\begin{tabular}{|c|c|c|c|}
\hline Ano & Modalidade de compra & Quantidade compras & Percentual \\
\hline & Convite & 3 & $0,14 \%$ \\
\hline \multirow[t]{7}{*}{2012} & Tomada de Preços & 10 & $0,45 \%$ \\
\hline & Concorrência & 7 & $0,32 \%$ \\
\hline & Pregão & 165 & $7,49 \%$ \\
\hline & Dispensa de Licitação & 1.916 & $87,01 \%$ \\
\hline & Inexigibilidade de Licitação & 101 & $4,59 \%$ \\
\hline & Tomada de Preços & 3 & $0,17 \%$ \\
\hline & Concorrência & 2 & $0,11 \%$ \\
\hline \multirow[t]{4}{*}{2013} & Pregão & 158 & $8,70 \%$ \\
\hline & Dispensa de Licitação & 1.559 & $85,85 \%$ \\
\hline & Inexigibilidade de Licitacão & 94 & $5,18 \%$ \\
\hline & Pregão & 174 & $12,76 \%$ \\
\hline \multirow[t]{2}{*}{2014} & Dispensa de Licitação & 1.151 & $84,38 \%$ \\
\hline & Inexigibilidade de Licitação & 39 & $2,86 \%$ \\
\hline
\end{tabular}

Fonte: Elaborado pelos autores a partir de Brasil (2015a)

Na IFES, verifica-se que as dispensas de licitação representaram um percentual ainda maior, superando os $80 \%$ em número de compras. No que diz respeito às compras realizadas pelo setor responsável dos materiais de consumo da IFES, no ano de 2014, tem-se os seguintes dados, conforme tabela 3.

Tabela 3 - Compras por modalidade realizadas pelo setor responsável por compras de material de consumo da IFES

\begin{tabular}{cccc}
\hline Ano & Modalidade de compra & Quantidade compras & Percentual \\
\hline \multirow{2}{*}{2014} & Pregão & 133 & $40,30 \%$ \\
& Dispensa de Licitação & 175 & $53,03 \%$ \\
& Inexigibilidade de Licitação & 22 & $6,67 \%$ \\
\hline & Fonte: Elaborado pelos autores a partir dos dados coletados durante a pesquisa
\end{tabular}

Nos órgãos do Governo Federal, quando da aplicação de filtro para exibir somente a exibição as aquisições realizadas por dispensa de licitação, percebe-se uma grande predominância da utilização do inciso II do artigo 24 da Lei 8.666/1993, conforme demonstra a tabela 4.

Tabela 4 - Compras por dispensa de licitação nos órgãos do Governo Federal

\begin{tabular}{lccc}
\hline Ano & Inciso Disp. Legal & Quantidade compras & Percentual \\
\hline \multirow{2}{*}{2012} & INCISO II & 163.735 & $90,46 \%$ \\
& Outrashipóteses & 17.259 & $9,54 \%$ \\
\hline \multirow{2}{*}{2013} & INCISO II & 151.123 & $89,87 \%$ \\
& Outrashipóteses & 17.029 & $10,13 \%$ \\
\hline \multirow{2}{*}{2014} & INCISO II & 129.614 & $89,11 \%$ \\
& Outrashipóteses & 15.833 & $10,89 \%$ \\
\hline
\end{tabular}

Fonte: Elaborado pelos autores a partir de Brasil (2015a)

Observa-se na tabela 4 que 0 inciso II do artigo 24 tem um percentual próximo dos $90 \%$. A mesma tendência é verificada nas aquisições realizadas na IFES em estudo, porém em um percentual um pouco menor, conforme tabela 5. 
Tabela 5 - Compras por dispensa de licitação na IFES

\begin{tabular}{lccc}
\hline Ano & Modalidade de compra & Quantidade compras & Percentual no Ano \\
\hline \multirow{2}{2012}{} & INASO II & 1.665 & $86,90 \%$ \\
& Outrashipóteses & 251 & $13,10 \%$ \\
\hline \multirow{2}{*}{2013} & INASO II & 1.320 & $84,67 \%$ \\
& Outrashipóteses & 239 & $15,33 \%$ \\
\hline \multirow{2}{*}{2014} & INCISO II & 966 & $83,93 \%$ \\
& Outrashipóteses & 185 & $16,07 \%$ \\
\hline
\end{tabular}

Fonte: Elaborado pelos autores a partir de Brasil (2015a)

Observando a tabela 5, verifica-se que o percentual na IFES em estudo também é alto, superando os $80 \%$ das dispensas de licitação, com base no inciso II do Art. 24 da lei.

Nas aquisições por dispensa de licitação, conduzidas pelo setor responsável pelas compras de material de consumo da IFES em estudo, o percentual chega próximo dos $60 \%$. A predominância não é tão grande tendo em vista 0 atendimento de pedidos de compra por dispensa de licitação utilizando recursos destinados à pesquisa científica, o qual é realizado por meio do disposto no inciso XXI do artigo 24 da Lei 8.666/1993 (Tabela 6).

Tabela 6 - Compras por dispensa de licitação realizadas pelo setor responsável pelas compras de material de consumo da IFES

\begin{tabular}{cccc}
\hline Ano Referência Compra & Inciso Disp. Legal & Quantidade Compras & Percentual \\
\hline \multirow{2}{*}{2014} & INCISOII & 104 & $59,43 \%$ \\
& Outras hipóteses & 71 & $40,57 \%$ \\
\hline
\end{tabular}

Fonte: Elaborado pelos autores a partir dos dados coletados durante a pesquisa

Assim, fica clara a importância da modalidade de aquisição por dispensa de licitação, utilizando o dispositivo do inciso II do artigo 24 da Lei 8.666/1993, considerando a quantidade de compras, tanto no âmbito de todo o Governo Federal, quanto na IFES estudada, inclusive naqueles processos conduzidos especificamente pelo setor responsável pelas compras de material de consumo da referida Instituição.

Quanto às limitações da pesquisa, ressalta-se que a realidade de outras instituições pode ser diferente, em decorrência do tamanho da instituição, da região onde atua ou mesmo pelas características próprias da organização. Além disso, há que se considerar também a época de realização da pesquisa.

\section{ANÁLISE DOS RESULTADOS}

Os instrumentos de pesquisa, o questionário e planilha $5 \mathrm{~W} 2 \mathrm{H}$, foram enviados para 5 pessoas que atenderam aos requisitos definidos na metodologia. Destas, 4 retornaram com os instrumentos respondidos. Em um momento preliminar da pesquisa, o questionário foi enviado aos entrevistados com o objetivo de traçar um perfil básico dos mesmos. As respostas dos entrevistados seguem no quadro 1.

Quadro 1 - Respostas do questionário de entrevista

\begin{tabular}{|l|l|}
\hline Perguntas & Respostas \\
\hline Quanto tempo atuam na IFES? & $\begin{array}{l}\text { Três entrevistados são servidores entre } 3 \text { a } 5 \text { anos. Um deles é servidor há aproximadamente } \\
7 \text { anos. }\end{array}$ \\
\hline Quanto tempo atua no Setor de Compras da IFES? & $\begin{array}{l}\text { Três entrevistados relataram que trabal ham no setor desde a sua posse, e um deles } \\
\text { respondeu que trabal ha desde maio/2012. }\end{array}$ \\
\hline $\begin{array}{l}\text { Entre suas atribuições, já realizou o processo de } \\
\text { compra direta (dispensa de licitação)? }\end{array}$ & Todos responderam que sim. \\
\hline $\begin{array}{l}\text { A compra direta (dispensa de licitação) está entre } \\
\text { suas atribuições atuais? }\end{array}$ & $\begin{array}{l}\text { Dos } 4 \text { entrevistados, apenas } 1 \text { respondeu que no momento não trabalha com este tipo de } \\
\text { compra. }\end{array}$ \\
\hline $\begin{array}{l}\text { Conhece os requisitos previstos na legislação } \\
\text { específica? }\end{array}$ & Todos os 4 responderam que consideravam que conheciam todo o processo. \\
\hline
\end{tabular}




\begin{tabular}{|l|l|}
\hline $\begin{array}{l}\text { Possui experiência com compras antes de ingressar } \\
\text { na IFES? }\end{array}$ & $\begin{array}{l}\text { Dois entrevistados responderam que não tinham experiência anterior; um respondeu que já } \\
\text { tinha experiência com compras em organização privada, e } 1 \text { respondeu que já tinha } \\
\text { experiência com organização pública ou de economia mista. }\end{array}$ \\
\hline $\begin{array}{l}\text { Descreva o processo de aprendizagem dos } \\
\text { procedimentos de compra direta. }\end{array}$ & $\begin{array}{l}\text { Em geral, todos responderam que aprenderam fazendo e pedindo ajuda aos colegas. Dois } \\
\text { deles responderam que aprenderam sozinhos; um deles relatou que teve um período de } \\
\text { treinamento e } 1 \text { que realizou alguns cursos de curta duração. }\end{array}$ \\
\hline $\begin{array}{l}\text { Utiliza alguma ferramenta ou técnica de gestão nos } \\
\text { procedimentos de compra direta? Qual(is)? }\end{array}$ & $\begin{array}{l}\text { Dois responderam que não tinham conhecimento, } 1 \text { deles citou o ErterpisePesarce } \\
\text { Paring(ERP) e CRM, e } 1 \text { respondente citou o satwerede gerenciamento de processos } \\
\text { utilizado pela IFES estudada, e também o mapeamento de processos. }\end{array}$ \\
\hline
\end{tabular}

Fonte: dados primários

0 segundo instrumento de pesquisa tinha por objetivo colher informações que possibilitassem o mapeamento do processo propriamente dito, por meio da planilha 5W2H. A partir destes dados, a planilha foi consolidada, tendo por resultado o fluxograma da figura 1, a seguir. 
Figura 1 - Fluxograma processo de compra pelo inciso II do artigo 24 da Lei 8.666/1993.

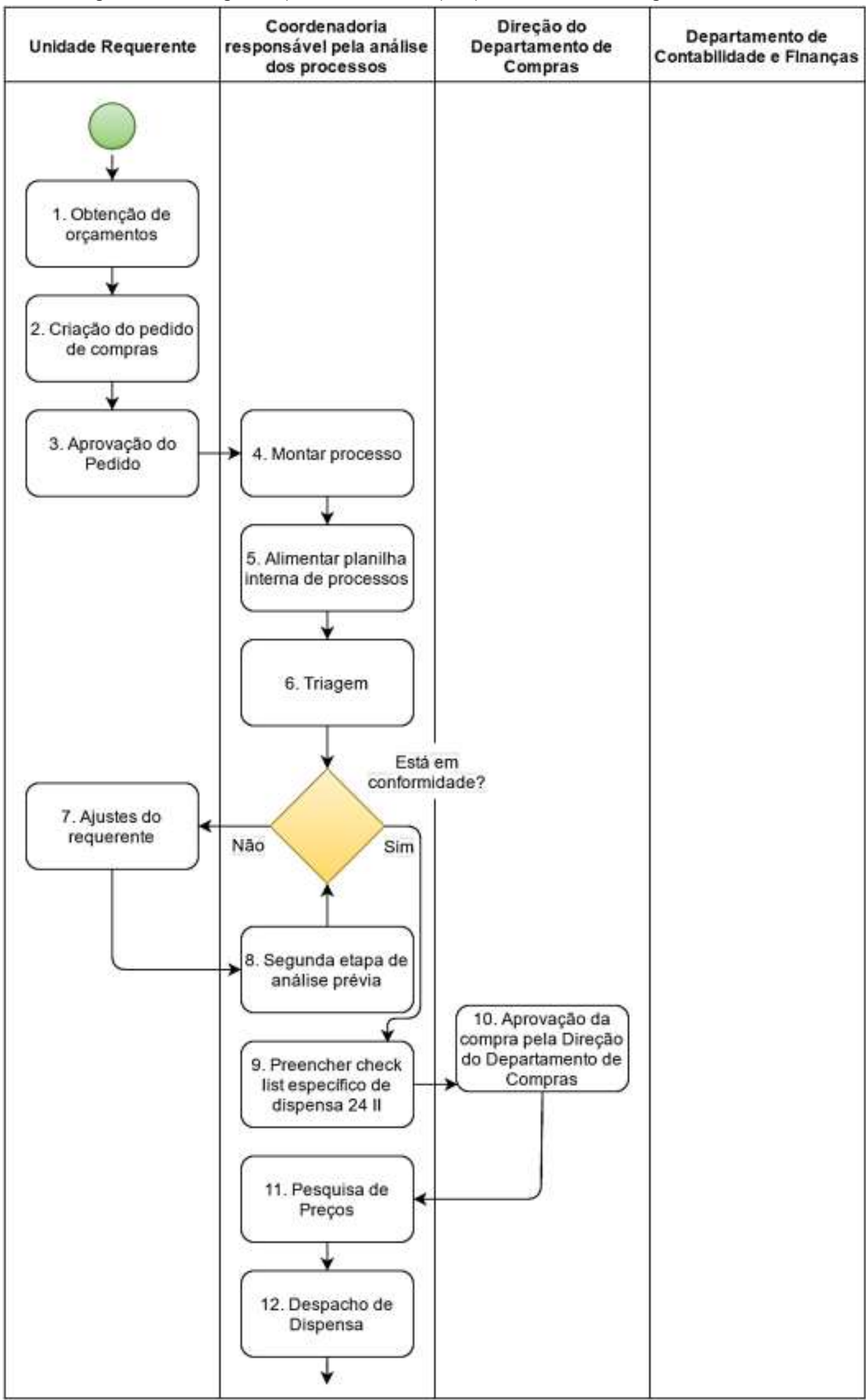




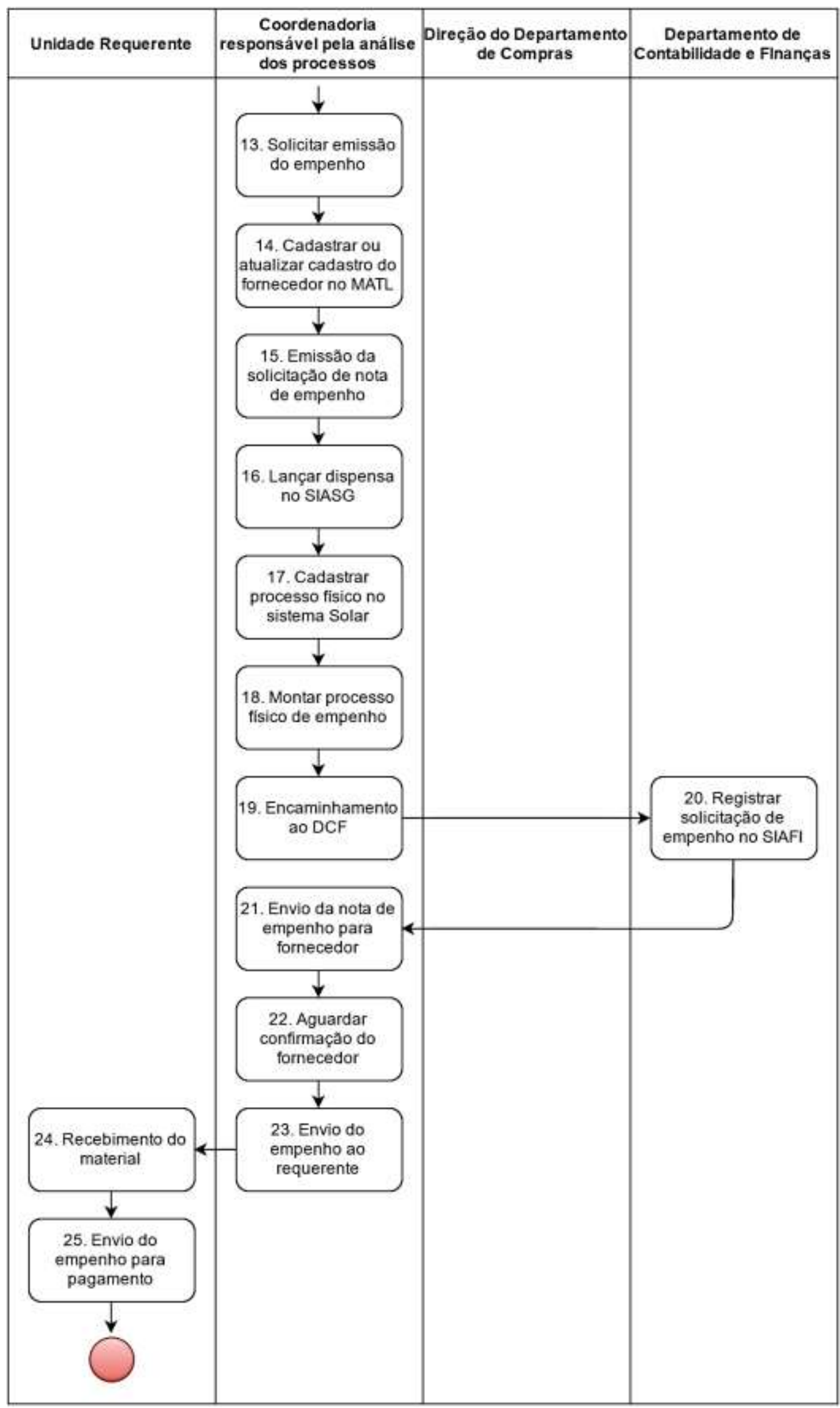

Fonte: Elaborado pelos autores (2017).

De modo geral, os respondentes da pesquisa tiveram uma visão semelhante, sendo que todos aparentaram conhecer o processo como um todo, detalhando um pouco mais as atividades em que tiveram maior 
tempo de experiência. Não aconteceram discrepâncias significativas nas informações repassadas por pessoas de diferentes coordenadorias, demonstrando que o processo possui um fluxo semelhante, seja para a aquisição de material de consumo ou material permanente.

Analisando o fluxograma da figura 1, foi possível perceber que a grande parte das atividades estão concentradas nas coordenadorias responsáveis por conduzir os processos. Dentre estas, destaca-se a atividade 11 (Pesquisa de Preços) que, segundo os entrevistados, poderia haver redução no tempo de atendimento se o software de gerenciamento dos processos digitais da IFES permitisse a importação dos dados já inseridos no sistema pelo requerente do material. Conforme os relatos, este tempo, que hoje fica em torno de 40 minutos, poderia ser reduzido em pelo menos $50 \%$.

Também se destaca a atividade seguinte, de número 12 (Despacho de Dispensa), que, apesar de ser relativamente rápida, poderia ser realizada de forma automática pelo software, conforme informações já inseridas anteriormente, o que, considerando o volume de processos, poderia auxiliar na redução do tempo de atendimento. Cabe destacar a utilização de dois softwares independentes para a realização de tarefas relacionadas. Em que pese a interface existente entre os dois softwares, os pesquisad os relataram ser muitas vezes ineficiente, uma vez que nem todas as informações são transferidas adequadamente, obrigando a inserção de dados manualmente.

Outro ponto que ressalta é o tempo necessário para a atividade 16 (Lançar Dispensa no SIASG). 0 tempo de atendimento pode aumentar muito, dependendo do sortimento de itens a serem comprados. A atividade 22 (Aguardar a Confirmação do Fornecedor) também pode comprometer o tempo de atendimento, visto que está sujeita a muitas interveniências, entre elas, caixa postal do fornecedor cheia, endereço de e-mail incorreto ou desatualizado no cadastro, entre outros fatores.

A quantidade de atividades evidencia a burocracia já esperada em um processo de compra pública, que segue um fluxo aparentemente truncado e pouco fluido. Além disso, todos os respondentes relataram durante as entrevistas que os softwares eram pouco eficientes e apresentavam instabilidades com relativa frequência, chegando a paralisar em certos momentos. Segundo eles, este fato acabava por afetar uma previsão mais exata dos tempos de atendimento em cada atividade.

\section{CONCLUSÃO}

As compras públicas são realizadas por meio de processos essencialmente burocráticos. A legislação impõe regras, entre as quais a exigência de licitação para a aquisição de materiais ou contratação de serviços. No entanto, em casos especiais, são permitidas compras com dispensa de licitação, como aqueles enquadrados no inciso II do artigo 24 da Lei 8.666/1993. 0 principal critério para a aquisição por este dispositivo é a limitação no valor de $\mathrm{R} \$ 8.000,00$ para a compra.

Através deste estudo foi possível inferir que as aquisições realizadas por dispensa de licitação no Brasil respondem por um significativo percentual em número de compras, superando, inclusive, o número de licitações realizadas. No caso específico da IFES, observou-se uma significativa porcentagem das compras sendo realizadas da mesma forma.

Ao comparar o número de dispensas realizadas pelo inciso II do artigo 24 da Lei 8.666/1993 com as outras hipóteses, verifica-se a predominância pelo inciso citado, justificando a necessidade de análise do processo de aquisição de materiais através deste dispositivo.

Por meio do fluxograma, foi possível verificar que há inconsistências e atividades que podem ser ajustadas, a fim de reduzir o tempo de atendimento, porém, existem outras atividades que devem ser estudadas em próximos trabalhos, contemplando a complexidade e as exigências legais envolvidas. Por fim, fica a recomendação da ampliação do estudo, com mais entrevistados e benchmarking em outras instituições, de modo a buscar o aperfeiçoamento ou melhoria do processo, a eliminação de tarefas desnecessárias, bem como 0 ajuste, otimização ou fusão de outras que são imprescindíveis. 


\section{REFERÊNCIAS}

AZEVEDO, J oel. A importância da gestão de processos no setor público. [2010]. Disponível em: $<$ <ttp://www.trf5.jus.br/downloads/Artigo_9_A_importancia_da_gestao_de_processos_no_set or_publico.pdf>. Acesso em 13 nov. 2015.

BRASIL. Constituição (1988). Constituição da República Federativa do Brasil. Braślia, DF: Senado Federal, 1988.

. Lei 8.666/1993, de 21 de junho de 1993. Regulamenta o art. 37, inciso XXI, da Constituição Federal, institui normas para licitações e contratos da Administração Pública e dá outras providências. Brasília, 21 jun. 1993. Disponível em: <http://www.planalto.gov.br/ccivil_03/Leis/L8666cons.htm>. Acesso em:09 nov. 2015.

DW-SIASG. 2015a.Disponível em: <http://dw.comprasnet.gov.br>. Acesso em: 20 nov. 2015.

Sistema Integrado de Administração de Serviços Gerais - SIASG. 2015b. Disponível em: $<$ <ttp://www.governoeletronico.gov.br/acoes-e-projetos/comprasgovernamentais/sistema-integrado-deadministracao-de-servicos-gerais-2013-siasg >. Acesso em: 15 dez. 2015.

CORREIA, Kwami Samora Alfama; LEAL, Fabiano; ALMEIDA, Dagoberto Alves de. Mapeamento de processo: uma abordagem para análise de processo de negócio. In: XXII Encontro Nacional de Engenharia de Produção, 2002, Curitiba. Anais.... Curitiba: 2002. Disponível em:

<http://www.abepro.org.br/biblioteca/ENEGEP2002_TR10_0451.pdf>. Acesso em:11 dez. 2015.

DAVENPORT, Thomas H. Reengenharia de processos: como inovar na empresa através da tecnologia da informação. Rio de Janeiro: Campus, 1994. 391 p. ISBN 8570018746.

GASPARINI, D. Direito Administrativo. 15. ed. São Paulo: Saraiva, 2010.

GONÇALVES, J osé Ernesto Lima. As empresas são grandes coleções de processos. RAE - Revista de Administração de Empresas, São Paulo, v. 40, n. 1, p. 6-19, jan./mar. 2000.

HAMMER, Michael. Além da reengenharia: como organizações orientadas para processos estão mudando nosso trabalho e nossas vidas. Rio de Janeiro: Campus, 1997. 249 p. ISBN 8535201076.

HARRINGTON, H. James. Business process improvement. New York: McGraw Hill, 1991.

IBM do Brasil. Enfoque de qualidade no processo de negócio. Rio de J aneiro, 1990.

JULIATTO, Dante Luiz et al. Implantação de modelo de gestão baseada em processos em uma universidade federal. In: SIMPÓSIO DE ENGENHARIA DE PRODUÇÃO, 19., 2012, Bauru. Anais... Bauru: UNESP, 2012.

LAKATOS, Eva Maria. Técnicas de pesquisa. 2. ed. São Paulo: Atlas, 1990.

LOSEKANN, Andresa Girardi et al. Análise e mapeamento de processo em uma instituição pública de ensino superior. In: Simpósio de Ensino, Pesquisa e Extensão, 2012, Santa Maria. Anais... . Santa Maria: 2012. Disponível em: <http://www.unifra.br/eventos/sepe2012/Trabalhos/5444.pdf>. Acesso em: 09 dez. 2015.

MARTIN, James. Cybercorp. New York: Amacom, 1996.

MONTEIRO, J ose A. Qualidade total no serviço público: questionamentos e recomendações segundo os 14 pontos de W. E. Deming. Brasília, DF: QA\&T, 1991. 157 p.

NUNES, Rogério da Silva. Análise e melhoria de processos. Florianópolis: Departamento de Ciências da Administração / UFSC, 2014. 143 p.

OLIVEIRA, Djalma de Pinho Rebouças de. Administração de Processos: conceitos, metodologia, práticas. 2. ed. São Paulo: Atlas, 2007. 
PAIM, Rafael et al. Gestão de processos: pensar, agir e aprender. Porto Alegre: Bookman, 2009. 327 p. ISBN 9788577804849 .

PONTIFÍCIA UNIVERSIDADE CATÓLICA DE MINAS GERAIS (PUCMG). DW. 2015. Disponível em: $<$ <ttp://www.pucminas.br/dw/index_padrao.php?PHPSESSID=f157b67910440c5ee7069d0f7 e7efb00>. Acesso em: 15 dez. 2015.

SMITH, H.; FINGAR, P. Business Process Management: the third wave. Florida: Meghan-Kiffer, 2003.

VERGARA, Sylvia Constant. Projetos e relatórios de pesquisa em administração. 10. ed. São Paulo: Atlas, 2009.

VERNER, L. BPM: The Promise and Challenge. v. 2, n. 1. USA: DSP, 2004.

VILLELA, Cristiane da Silva Santos. Mapeamento de processos como ferramenta de reestruturação e aprendizado organizacional. 2000. 182 f. Dissertação (Mestrado) - Curso de Engenharia de Produção, Departamento de Engenharia de Produção e Sistemas - Universidade Federal de Santa Catarina, Florianópolis, 2000. Disponível em:

<https://repositorio.ufsc.br/bitstream/handle/123456789/78638/171890.pdf?sequence=1>. Acesso em: 09 dez. 2015. 